\title{
Renal cysts and diabetes syndrome
}

INSERM

\section{Source}

INSERM. (1999). Orphanet: an online rare disease and orphan drug data base. Renal cysts and diabetes syndrome. ORPHA:93111

Renal cysts and diabetes syndrome (RCAD) is a rare form of maturity-onset diabetes of the young (MODY; see this term) characterized clinically by heterogeneous cystic renal disease and early-onset familial non-autoimmune diabetes. Pancreatic atrophy, liver dysfunction and genital tract anomalies are also features of the syndrome. 